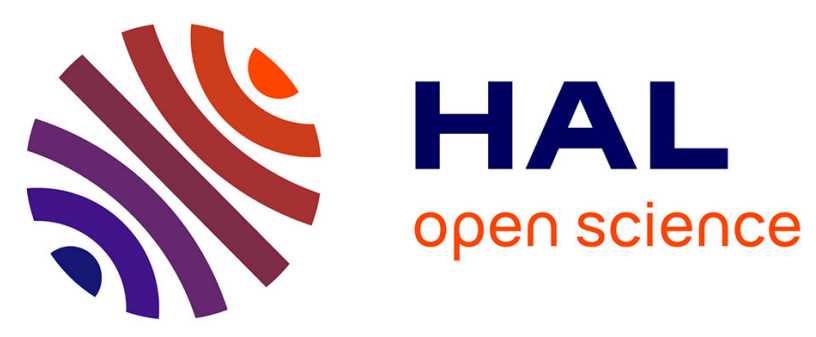

\title{
Assessing the response of satellite sun-induced chlorophyll fluorescence and MODIS vegetation products to soil moisture from 2010 to 2017: a case in Yunnan Province of China
}

Zhuoya Ni, Hongyuan Huo, Shihao Tang, Zhao-Liang Li, Zhigang Liu, Shan $\mathrm{Xu}$, Binglong Chen

\section{To cite this version:}

Zhuoya Ni, Hongyuan Huo, Shihao Tang, Zhao-Liang Li, Zhigang Liu, et al.. Assessing the response of satellite sun-induced chlorophyll fluorescence and MODIS vegetation products to soil moisture from 2010 to 2017: a case in Yunnan Province of China. International Journal of Remote Sensing, 2019, 40 (5-6), pp.2278-2295. 10.1080/01431161.2018.1506186 . hal-02377734

\author{
HAL Id: hal-02377734 \\ https://hal.science/hal-02377734
}

Submitted on 8 Dec 2020

HAL is a multi-disciplinary open access archive for the deposit and dissemination of scientific research documents, whether they are published or not. The documents may come from teaching and research institutions in France or abroad, or from public or private research centers.
L'archive ouverte pluridisciplinaire HAL, est destinée au dépôt et à la diffusion de documents scientifiques de niveau recherche, publiés ou non, émanant des établissements d'enseignement et de recherche français ou étrangers, des laboratoires publics ou privés. 


\section{Assessing the response of satellite sun-induced chlorophyll fluorescence and MODIS vegetation products to soil moisture from 2010 to 2017: a case in Yunnan Province of China}

Zhuoya $\mathrm{Ni}^{\mathrm{a}}$, Hongyuan $\mathrm{Huo}^{\mathrm{b}}$, Shihao Tang ${ }^{\mathrm{a}}$, Zhao-Liang $\mathrm{Li}^{\mathrm{b}, \mathrm{c}}$, Zhigang Liu ${ }^{\mathrm{d}}$, Shan $\mathrm{Xu}$ and Binglong Chen ${ }^{\mathrm{a}}$

aKey Laboratory of Radiometric Calibration and Validation for Environment Satellites, National Satellite

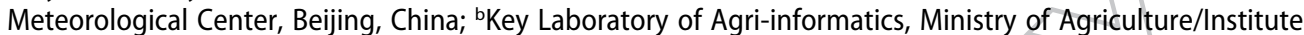
of Agricultural Resources and Regional Planning, Beijing, China; ‘Cube, CNRS, Université de Strasbourg, Illkirch, France; ${ }^{d}$ State Key Laboratory of Remote Sensing Science, Institute of Remote Sensing Science and Engineering, Faculty of Geographical Science, Beijing Normal University, Beijing, China

\begin{abstract}
Sun-induced chlorophyll fluorescence (SIF) is widely used to monitor vegetation physiological conditions. In this paper, SIF derived from the Global Ozone Monitoring Experiment-2 (GOME-2), and gross primary productivity (GPP), normalized difference vegetation index (NDVI), land surface temperature (LST), soil moisture and precipitation are used to investigate vegetation stress in six areas of Yunnan Province in China. The results illustrate that SIF, NDVI, and GPP all decrease in the condition of water stress and increase when recovering towards a healthy condition; LST increases under stress conditions and decreases gradually during recovery conditions. Then, analyses of long timeseries for SIF, GPP, NDVI, and LST from 2010 to 2017 are conducted. These performances demonstrate SIF is much more sensitive than GPP, the NDVI, and LST during drought conditions. When vegetation is in the condition of water stress, SIF has earlier responses than other parameters. Last, the relationships between SIF and soil moisture in 2010-2016 yield significant results, with the correlation coefficient $r=0.56,0.71,0.75,0.74,0.62,0.52$ and 0.47 , sequentially. The correlation coefficients are used to measure how strong a relationship is between two variables. This work demonstrates that SIF is a good way to monitor water condition change, and may play a great role in drought monitoring in the future.
\end{abstract}

\section{ARTICLE HISTORY}

Received 8 January 2018 Accepted 16 July 2018

\section{Introduction}

For the study of drought, a great deal of work has been performed in China and internationally. Foreign countries started research at the end of the 19th century, and China started research at the beginning of the 20th century. Droughts in many parts of the world have greatly impacted socio-economic systems and the environment (IPCC 2001). Drought is one of

CONTACT Hongyuan HUO hongyuanh@gmail.com $\Theta$ Key Laboratory of Agri-informatics, Ministry of Agriculture/ Institute of Agricultural Resources and Regional Planning, Chinese Academy of Agricultural Sciences, Beijing 100081, China 
the major disturbances to vegetation growth, as it may weaken the ability of vegetation to function as a carbon sink (Xu et al. 2011; Wang et al. 2015).

Yunnan Province, which is located in southeast China and historically has a moist climate, is reported to have had drought events in recent years. A severe and sustained drought hit Yunnan Province in southwest China, from autumn 2009 until spring 2010, resulting in $\$ 2.5$ billion of agricultural damage and a shortage of drinking water for about 9.65 million people (Qiu 2010). It is very important to monitor and predict the droughts accurately for protecting socio-economic stability and agriculture (Ma et al. 2017).

Drought, which affects plant growth and production, is a significant issue and attracts the attention of many researchers (Peters et al. 2002; Wang and Qu 2009b). Many researchers use optical and thermal infrared remote sensing, as well as passive and active microwave remote sensing techniques, to monitor drought (Fuchs and Tanner 1966; Jackson et al. 1981; Paloscia and Pampaloni 1984; Hunt and Rock 1989; Gao 1996; Walker 1999; Peters et al. 2002; Sandholt, Rasmussen, and Andersen 2002; Wang and Qu 2009b; Vereecken et al. 2012); these methods exploit surface reflectance, surface temperature, brightness, temperature and the backscatter coefficient separately to estimate soil moisture near the surface. Although these methods are widely used, they have several limitations, which are mainly exploiting the appeared feature of vegetation without considering the relationship between these factors or the vegetation physiological condition. Chlorophyll fluorescence is induced by solar illumination and is used to consume absorbed energy through two other processes (i.e. photochemistry and heat dissipation) (Lichtenthaler \& Miehe 1997; Porcar-Castell et al., 2014). Therefore, suninduced chlorophyll fluorescence (SIF) is thought to be a direct probe to monitor vegetation physiological condition. In recent years, chlorophyll fluorescence is widely used to understand vegetation photosynthesis, detect drought and estimate gross primary production, all of which have gradually become a hot research topic.

Near the ground, chlorophyll fluorescence is measured to illustrate vegetation water stress in water-control experiments, and the results show that chlorophyll fluorescence is sensitive to changes in water content and decreases in water stress (Rosema et al. 1998; Flexas et al. 2000, 2002; Zarco-Tejada et al., 2002; Marcassa et al. 2006; Meroni et al. 2009; Dobrowski et al. 2005; Pérez-Priego et al. 2005; Campbell et al. 2007; Zarco-Tejada et al. 2009; Zarco-Tejada, González-Dugo, and Berni 2012; Bürling et al. 2013, 2013; Ni et al. 2015a). Under water stress conditions, plants close their stomata to decrease their net photosynthesis rate in order to avoid further water loss; photosynthetic pigment contents also change in response to water stress, which is associated with photosystem II (Rahbarian, Khavari-Nejad, and Ganjeali et al. 2011). Changes in the proportion of photochemical and energy-dependent quenching leads to alterations in fluorescence kinetics under water stress (Zlatev and Yordanov 2004). The absorbed energy is used to derive photosynthesis, emit chlorophyll fluorescence, and dissipate heat. These three processes complete each other, and chlorophyll fluorescence is inversely related to photosynthesis activity (the 'Kautsky effect'), which decreases with an increase in photosynthesis, and vice versa (Smorenburg et al. 2002).

After the first global maps of SIF are produced (Frankenberg et al. 2011b; Guanter et al. 2012; Joiner et al. 2011, 2012), SIF has been used to estimate gross primary productivity (GPP) (Damm et al. 2014, 2015; Cheng et al. 2013; Guanter et al. 2014; Zhang et al. 2014, 2016; PerezPriego et al. 2015; Yang et al. 2015; Guan et al. 2016; Thum et al., 2016) and detect vegetation 
stress (Lee et al., 2013; Browning et al., 2014; Sun et al., 2015; Yoshida et al., 2015; Wang et al., 2016). Lee et al. (2013) analysed the variations in Greenhouse gases Observing Satellite (GOSAT)SIF and GPP in Amazonia and showed that the satellite measurement of fluorescence is more sensitive to variations in chlorophyll content than vegetation indices and can improve the GPP estimation accuracy. Sun et al. (2015) illustrated that satellite SIF can be used to detect drought through Global Ozone Monitoring Experiment-2 (GOME-2) SIF, fraction of photosynthetically active radiation (FPAR), soil water content and climate variables in the case of droughts in 2011 in Texas and in 2012 over the central Great Plains. Yoshida et al. (2015) analysed the response of SIF to a Russian drought and heat wave in 2010 using satellite SIF and simulated SIF and GPP. Wang et al. (2016) examined the relationship between satellite SIF and meteorological drought indices and analysed the variations in SIF and other relative parameters in a 2012 drought that occurred in the Great Plains.

In this paper, the objective is to analyse the variation of satellite SIF, Moderate Resolution Imaging Spectroradiometer (MODIS) vegetation products under different water condition in Yunnan Province from 2010 until 2017. Satellite SIF is retrieved from the GOME-2 by Joiner et al. (2013, 2014). GOME-2 SIF data combined with MODIS GPP, normalized difference vegetation index (NDVI), land surface temperature (LST), soil moisture and precipitation from the six research sites in Yunnan Province are used to show the response of these parameters to soil moisture. Through long time series analysis of these data, we can demonstrate clearly the change of these parameters along with the variation of soil moisture and precipitation. Comparisons between SIF and NDVI or GPP or LST show that SIF can reflect the vegetation condition change earlier that other parameters under the condition of water stress. It also demonstrates that SIF is much more sensitive to water content change than other common vegetation monitoring ways. Thus, SIF is thought to be effective and direct proxy to monitor the vegetation physiological state, and used in many applications.

\section{Study areas}

The study areas are located in Yunnan Province of southwest China. The northern region of Yunnan province forms part of the Yun-Gui Plateau and borders the Tibet Autonomous Region to the northwest. The eastern part of the province is a limestone plateau with karst topography and unnavigable rivers that flow through deep mountain gorges. The western half of Yunnan is characterized by mountain ranges and rivers running north and south. The mainland region of this study area is composed of croplands, trees, and grass. Yunnan Province has a generally mild climate with pleasant and fair weather. Under the Köppen climate classification, most of the study area is located in a subtropical highland (Köppen classification of $\mathrm{Cwb}$ ) or a humid subtropical zone (Cwa).

Figure 1 shows the location of the study area. In this paper, a region of heavy drought is selected as the study area and includes the Chuxiong Yi Autonomous Prefecture, Yuxi, Honghe Hani and the Yi Autonomous Prefecture, Qujing, Wenshan Zhuang and the Miao Autonomous Prefecture, and Kunming. From 2009 to 2012, continuous heavy droughts occurred in the abovementioned regions; during this time, many extreme climate conditions occurred. In this study, the variations of GOME-SIF, MODIS LST, GPP and other climate parameter data in these regions are analysed. Figure 1 shows the research 


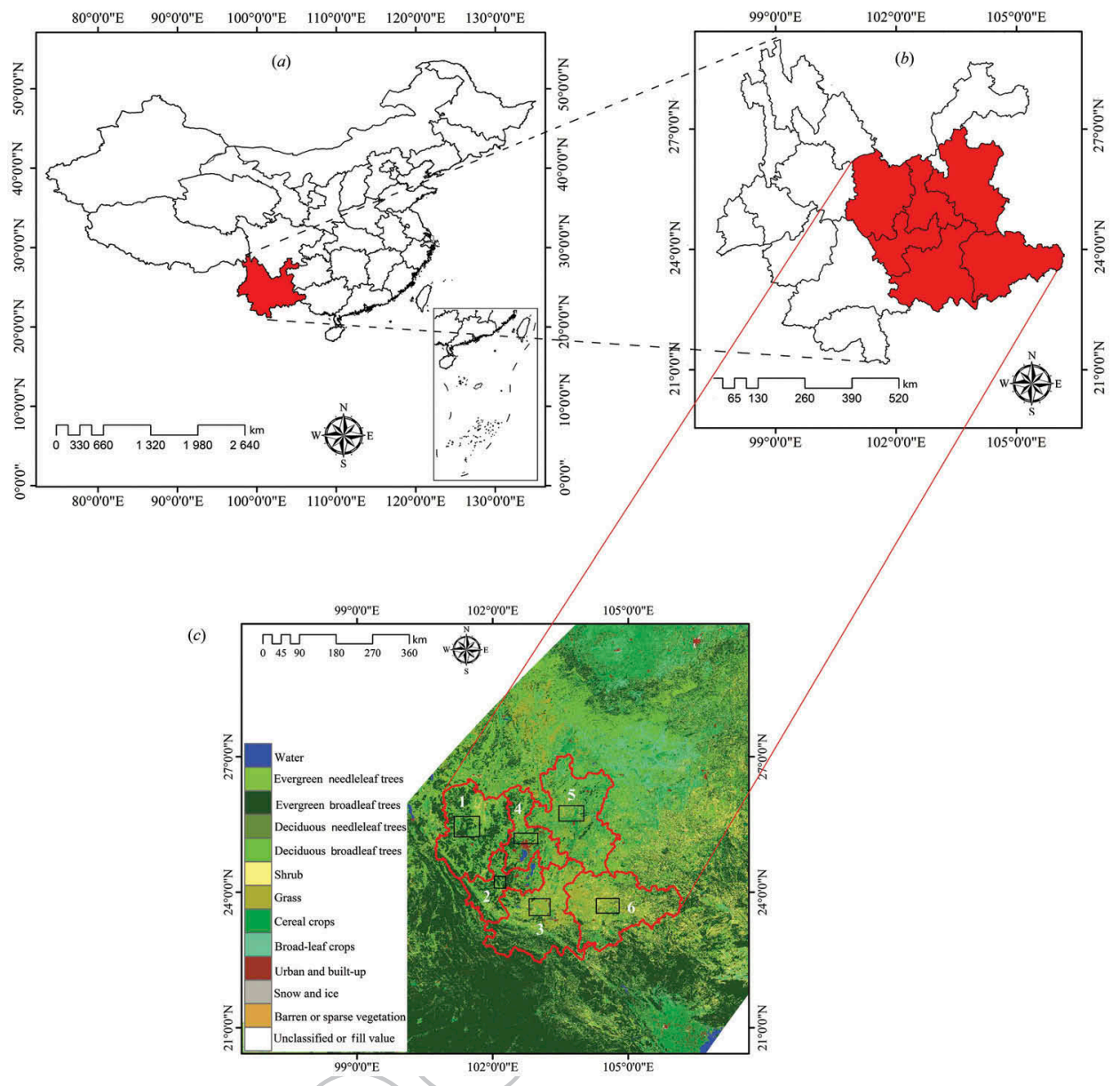

Figure 1. Research sites.

sites, which are covered by different types of vegetation. The data in the black box is counted in the following analysis.

\section{Materials and methods}

\subsection{Methodology}

Due to the close relationship between SIF and photosynthesis, SIF is regarded as an important way to investigate vegetation response to drought. NDVI and GPP are widely used to reflect the vegetation status. NDVI is calculated from the visible and nearinfrared light reflected by vegetation, and GPP is mostly estimated through light use efficiency and photosynthetically active radiation (PAR) (Monteith 1972) or vegetation indices (Wu et al., Wu, Niu, and Gao 2010). Different variations in SIF, the NDVI, GPP and LST from 2010 to 2017 are analysed to illustrate the advantages of SIF when monitoring plant physiological state. In addition, the model analysis is carried out to show vegetation responses to different stress levels and can provide support for the following 


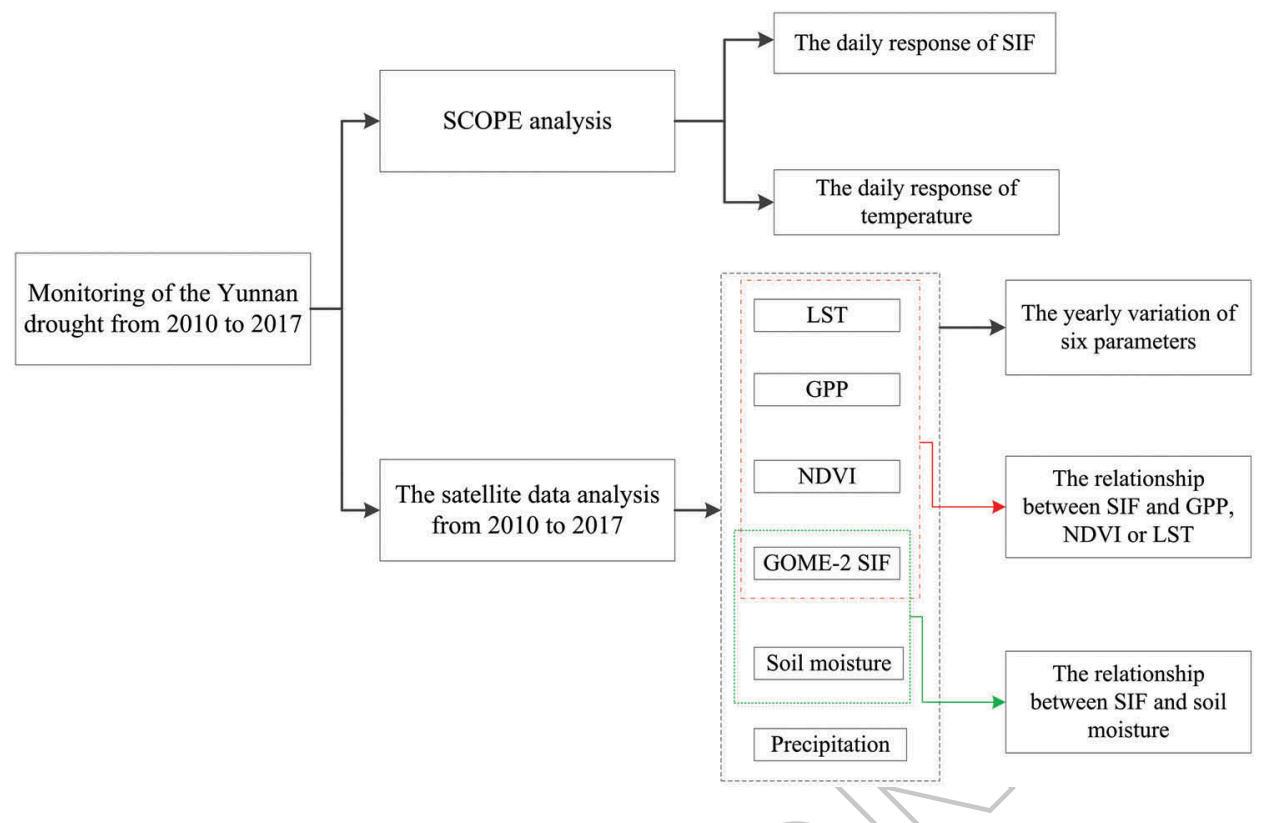

Figure 2. Flow chart.

analysis in Yunnan Province of China. Drought leads to soil moisture deficit, stomatal closure and reduction in photosynthesis and transpiration, and causes the chlorophyll fluorescence to decrease. Therefore, the relationship between chlorophyll fluorescence and soil moisture is analysed. The structure of this paper as follows:

\subsection{Soil canopy observation, photochemistry and energy fluxes (SCOPE) model}

The aim of SCOPE model is to simulate the radiative transfer and energy balance from 0.4 to $50 \mu \mathrm{m}$. A surprised module of SCOPE is that it can simulate canopy fluorescence through the radiation transfer module and leaf biochemical model. FluorMOD, can also simulate the canopy fluorescence radiance (Zarco-Tejada et al. 2004a; Zarco-Tejada 2005; Miller et al. 2005; Ni et al. 2015b), but it is only used under healthy conditions. In SCOPE model, stress factor (SF) is set to express stress factor that reduces the maximum carboxylation capacity $\left(V_{\text {cmax }}\right)$ in a biochemical module (e.g. soil moisture and leaf age). $V_{\text {cmax }}$ is an essential parameter for photosynthesis. Through the different SF in SCOPE model, the responses of SIF and temperature can be observed. In SCOPE model, the relative parameters are set using default parameters ( $\mathrm{Ni}$ et al. 2015a, 2016).

\subsection{GOME-2 SIF data}

The SIF products retrieved from the Global Ozone Monitoring Instrument 2 (GOME-2) onboard the EUMETSAT Meteorological Operational satellite program (MetOp-A) by Joiner et al. $(2013,2014)$ are used in this research. Joiner et al. used a simplified radiative transfer model with an empirically-based principal component analysis approach to retrieve global far-red fluorescence information from a broad spectral 
range of 734-758 $\mathrm{nm}$. The monthly global fluorescence data (Level 3), with a spatial resolution $0.5^{\circ} \times 0.5^{\circ}$, derives from version 27 of the dataset and covers the period from 2007 to 2017. Here, global fluorescence data from 2010 to 2017 in Yunnan Province are used.

\subsection{Modis data}

In this paper, GPP data sets, NDVI, and LST products, which all derive from MODIS data, are used. The products corresponding to these above datasets are MOD17A2H, MOD13A3, and MYD11C3, respectively. Global data sets of 8-day composites from 2010 to 2017 are selected for use in this paper. These parameters can reflect the vegetation 'green' information and are widely used to monitor the drought due to the sensitivity to variations in soil moisture. The GPP, the NDVI and LST are used to illustrate the response to soil moisture change when combined with fluorescence.

\subsubsection{GPP dataset}

The temporal-spatial distribution of terrestrial GPP and its variability have a close relationship with the Earth's carbon budget. Terrestrial chlorophyll fluorescence has a direct relationship with photosynthetic fluorescence and has recently been used to estimate GPP (Damm et al. 2014, 2015; Cheng et al. 2013; Guanter et al. 2014; Zhang et al. 2014, 2016; Perez-Priego et al. 2015; Yang et al. 2015; Guan et al. 2016; Thum et al. 2017). Due to the relationship between fluorescence and GPP, fluorescence can be regarded as having the potential to monitor the vegetation condition and assess the terrestrial carbon budget. Recent advances in the remote sensing of SIF has opened up a new possibility of providing direct global observation constraints for GPP. The GPP dataset, MOD17A2H, which is an 8-day composite at a spatial resolution of $1 \mathrm{~km}$ $\times 1 \mathrm{~km}$ from 2010 to 2017 , is used in this study to show the relationships among fluorescence, GPP and soil moisture. According to the data acquired date, the products in the same month are averaged to represent the monthly GPP value.

\subsubsection{LST dataset}

LST is thought of as a useful indicator when monitoring the variations in soil moisture and is widely used in the application of the drought. In this paper, the LST product derived from MODIS is used to comprehensively analyse the relationship between LST and soil moisture. The MOD11L2 dataset is a monthly product with a spatial resolution of $5 \mathrm{~km}$ that is produced from the 8-day MODIS LST products, and the time range is also from 2010 to 2017.

\subsubsection{NDVI dataset}

Vegetation index, NDVI, is one of the most prominent indicators when monitoring the health and vigour of vegetation. To make a comparison between the drought sensitivity of SIF and the reflectance-based vegetation indices, NDVI is taken as a reference. A coarser spatial resolution of $500 \mathrm{~m}$ for NDVI product is retrieved from the MODIS reflectance dataset, which ranges from 2010 to 2017. It is noted that NDVI dataset is resampled to $5 \mathrm{~km}$ in an attempt to be consistence with the other datasets. 


\subsection{Soil moisture data}

The active soil moisture product covered from 1978 to 2016 is produced by the Earth Observation Data Centre for Water Resources Monitoring GmbH (EODC) and is the output after merging the scatterometer-based soil moisture data, which derived from the Active Microwave Instrument Wind Scatterometer (AMI-WS) and Advanced Scatterometer (ASCAT, Metop-A and Metop-B, respectively) (Liu et al. 2011; Liu and Dorigo et al. 2012; Wagner et al. 2012); this product has a global coverage and a spatial resolution of $0.25^{\circ}$, a temporal resolution of 1 day and a reference time at 0:00 UTC (product specification document (PSD) Q1.2.1, version 3.3). The soil moisture data for the active product are expressed by the percent of saturation (\%). The soil moisture content field-measured data are different to obtain; therefore, the satellite-derived dataset is used to illustrate the soil moisture content from 2010 to 2016 in the Yunnan Province in China.

\subsection{Precipitation data}

The precipitation data are produced using a thin plate spline method based on precipitation data from 2472 weather stations, including the national benchmark climate station, the national basic weather station and the national general weather station of China by the National Meteorological Information Center of the China Meteorological Administration. The dataset is a monthly grid with a spatial resolution of $0.5^{\circ} \times 0.5^{\circ}$ in China from 1961 to 2017. Here, precipitation data from 2010 to 2017 are selected. The datasets used in this paper are summarized in Table 1.

\section{Results and discussions}

\subsection{The daily response of SIF to soil moisture from the model analysis}

The SCOPE model is used to simulate the daily variation of fluorescence and temperature under different stress levels. SF is defined as the stress factor that reduces the maximum carboxylation capacity $\left(V_{c \max }\right)$ in a biochemical module (e.g. soil moisture and leaf age). When the plant is under a healthy condition, SF equates to 1.0. When the SF values increase, the stress deepens. A daily analysis is used to illustrate the response of

Table 1. Products used in this study.

\begin{tabular}{|c|c|c|c|c|}
\hline Products & $\begin{array}{l}\text { Spatial } \\
\text { resolution }\end{array}$ & $\begin{array}{l}\text { Temporal } \\
\text { resolution }\end{array}$ & Unit & Source \\
\hline GOME-2 SIF & $0.5^{\circ} \times 0.5^{\circ}$ & monthly & 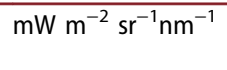 & $\begin{array}{l}\text { https://avdc.gsfc.nasa.gov/pub/data/satellite/ } \\
\text { MetOp/GOME_F/v27/MetOp-A/level3/ }\end{array}$ \\
\hline GPP (MOD17A) & $0.005^{\circ} \times 0.005^{\circ}$ & 8-days & $\mathrm{kgC} \mathrm{\textrm {m } ^ { - 2 }}$ & $\begin{array}{l}\text { https://search.earthdata.nasa.gov/search?m=7. } \\
59375 ! 15.64453125 ! 4 ! 1 ! 0 ! 0 \% 2 C 2\end{array}$ \\
\hline LST (MYD11C3) & $0.05^{\circ} \times 0.05^{\circ}$ & monthly & K & $\begin{array}{l}\text { https://search.earthdata.nasa.gov/search?m=7. } \\
59375 ! 15.64453125 ! 4 ! 1 ! 0 ! 0 \% 2 C 2\end{array}$ \\
\hline NDVI (MOD13A) & $0.01^{\circ} \times 0.01^{\circ}$ & 8-days & Relative unit & $\begin{array}{l}\text { https://search.earthdata.nasa.gov/search?m=7. } \\
59375 ! 15.64453125 ! 4 ! 1 ! 0 ! 0 \% 2 C 2\end{array}$ \\
\hline Soil moisture & $0.25^{\circ} \times 0.25^{\circ}$ & monthly & $\%$ & ftp.geo.tuwien.ac.at \\
\hline Precipitation & $0.5^{\circ} \times 0.5^{\circ}$ & monthly & $\mathrm{mm}$ & $\begin{array}{l}\text { http://idata.cma/idata/web/data/index? } \\
\text { dataCode=SURF_CLI_CHN_PRE_MON_ } \\
\text { GRID_0.5 }\end{array}$ \\
\hline
\end{tabular}




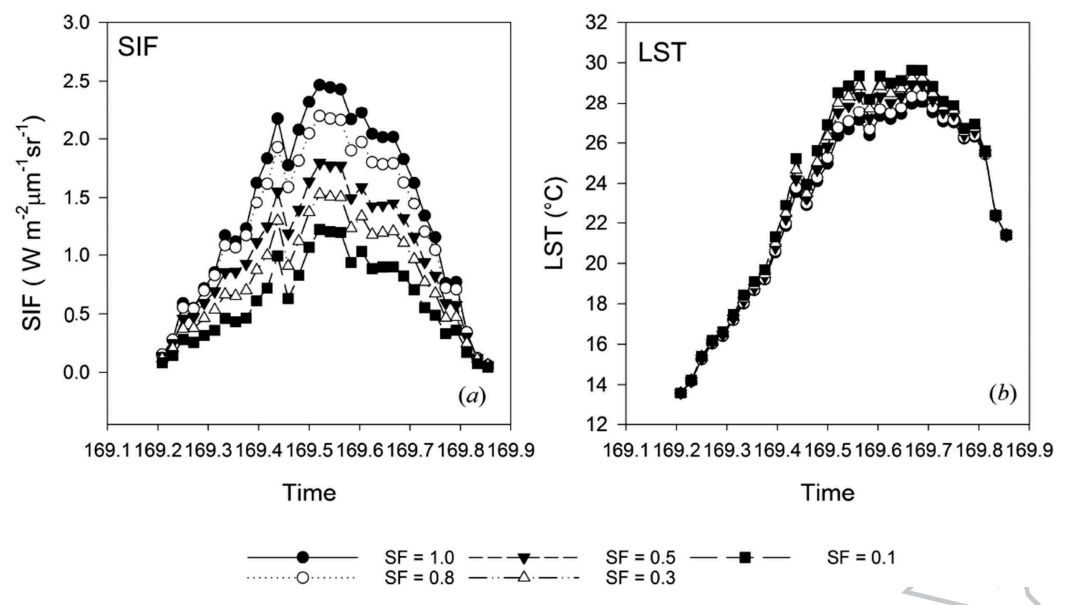

Figure 3. Daily changes in SIF and LST from the SCOPE model (the x-axis is in Julian days, where 24 hours are expressed from 0.0 to 1.0).

these parameters to different water conditions. When water stress deepens, SIF decreases (Figure 3a) and LST gradually increases (Figure 3b). In this work, the default data is used in this model simulation. Based on the theoretical model, the different daily responses of SIF and temperature are illustrated. Despite the annual variations in SIF and the other parameters are analysed in the following work, the model analysis still explains the response of SIF and temperature to different water contents.

\subsection{Annual variations in SIF and other relative parameters from 2010 to 2017}

To analyse the variation in SIF, the NDVI, precipitation, LST, GPP and soil moisture from 2010 to 2017, Chuxiong and Qujing are selected as the representative areas.

In Figure 4a, from January to December, the fluorescence first decreases, then increases to a peak, and finally decreases. The minimum values occur mostly in May. The SIF changes intensely in 2010. SIF in the April to August in 2010 is less than same period in 2011. From 2011 to 2014, fluorescence decreases gradually, and from 2014 to 2017, fluorescence increases. This also shows the dynamic change in SIF in the Chuxiong district and indirectly illustrates the recovery process of the vegetation condition.

Figure $4 \mathrm{f}$ shows that the soil moisture increases gradually from 2010 to 2016. It clearly changes from 2010 to 2013 and varies slightly from 2014 to 2016. It also reveals that the Chuxiong district undergoes a long relief process after a drought. In Figure 4c, the precipitation conditions are demonstrated. Precipitation is very low in 2010 and increases gradually. The annual variation in precipitation is sharp at first, then tends to become more stable.

It is widely accepted that when vegetation is under a water stress condition, the photosynthesis function increases slowly and fluorescence declines. Due to low soil moisture and precipitation in 2010, fluorescence changes rapidly and has a minimum value in May. From 2010 to 2014, despite the soil moisture and precipitation increase, fluorescence still declines. This illustrates that the water stress has not yet been relieved, 

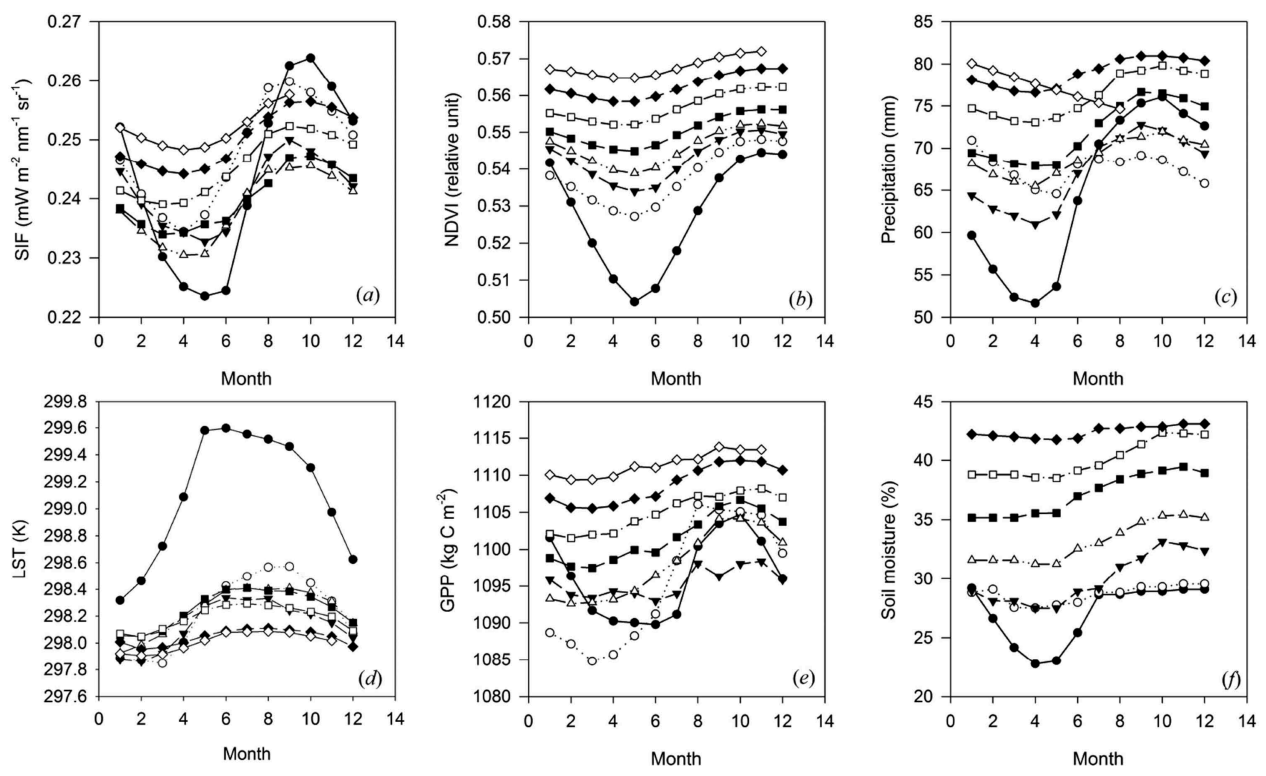

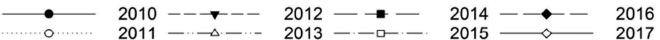

Figure 4. Variations in SIF, NDVI, precipitation, LST, GPP and soil moisture in the Chuxiong district (Yunnan Province, China).

and it is still deepening. Since 2014, fluorescence has an increasing trend and shows that vegetation is recovering towards a healthy condition.

Regarding the annual NDVI (Figure 4b), it decreases to a minimum value in June, then increases. Its variation reaches a minimum value later than that of SIF; in other words, SIF can reflect the vegetation physiological condition change earlier than that from NDVI. In any case, in 2010, the variation of NDVI is not remarkable, and SIF has a clear and noticeable change from 2010 to 2017. It is obvious that SIF is more sensitive than NDVI towards soil moisture change.

LST is higher under water stress conditions than that under healthy conditions. Similarly, in Figure 4d, LST in 2010 has a sharp change and is not remarkable in other years. The recovery process for LST is not obvious when compared with SIF. In Figure $4 \mathrm{e}$, the variation in GPP from 2010 to 2017 is shown. The minimum value of GPP is obtained in July. The variation in GPP in 2010 is significant; in other years, it is relatively stable.

When examining the variation in soil moisture, SIF, NDVI, LST and GPP have similar responses. When vegetation is under water stress conditions, SIF, NDVI and GPP decrease, and LST increases. These all have remarkable variations in 2010. Yunnan in 2010 suffered the worst drought; vegetation died, and crops failed during the drought. Low precipitation and a serious soil shortage led to a reduction in SIF, NDVI and GPP and an increase in LST.

In Figure 5, the above mentioned parameters from 2010 to 2017 in Qujing district are 275 shown. The conclusions obtained from Figure 5 are similar to those from Figure 4. Therefore, the relative analysis is not stated here. 

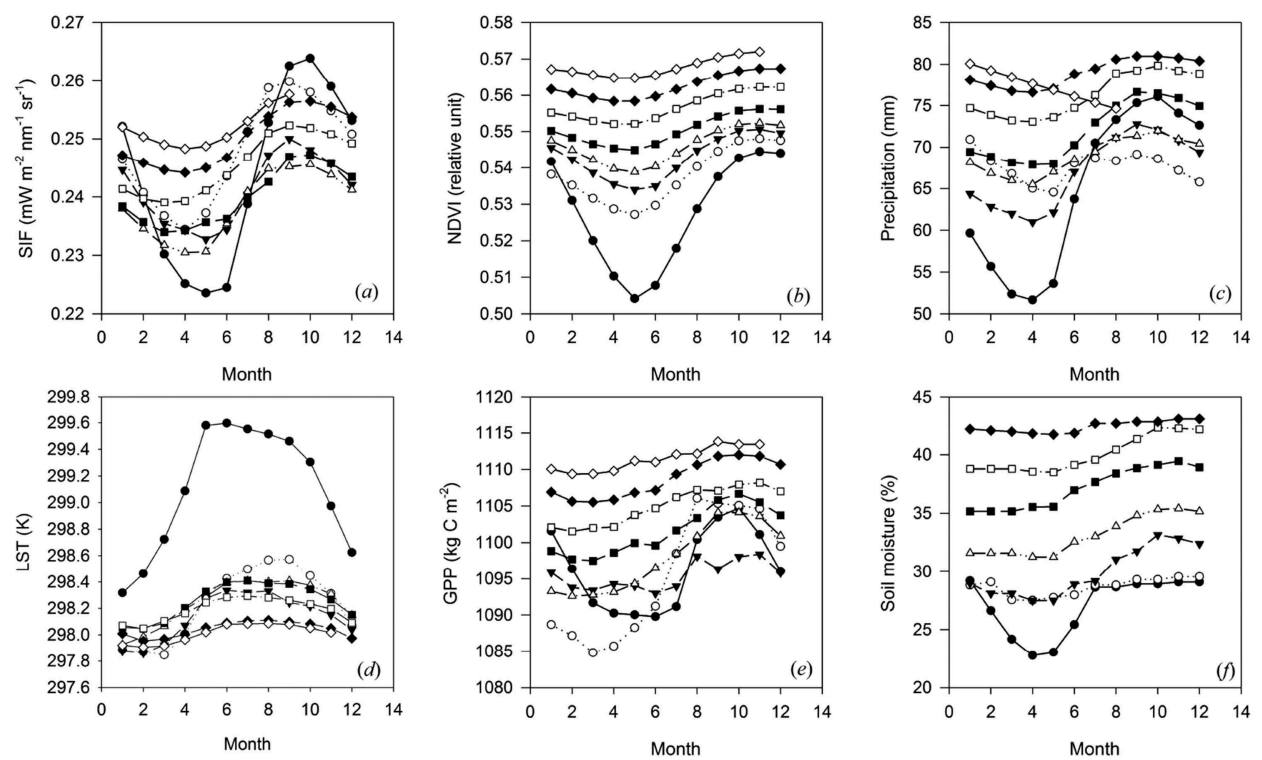

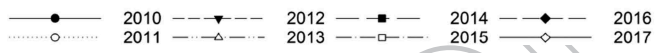

Figure 5. Variations in SIF, NDVI, precipitation, LST, GPP and soil moisture in the Qujing district (Yunnan Province, China).

\subsection{Comparisons between SIF and GPP, NDVI or LST}

GPP, NDVI and LST are widely used to monitor vegetation change, and SIF is thought of as an effective probe to detect vegetation physiological variations in recent years. To exhibit the potential of SIF in detecting water stress, comparisons between SIF and GPP, NDVI or LST are carried out.

In Figure 6, it can be seen that variation in SIF is much more intense than variation in GPP. This also illustrates that SIF is much more sensitive than GPP to changes in the vegetation physiological state. The satellite-based GPP is mostly estimated using a lightuse efficiency (LUE) approach, which refers to the incident of photosynthetically active radiation, the fraction of PAR absorbed by the vegetation canopy and the light use efficiency. Compared with SIF, GPP is a complicated parameter that has a relationship with global meteorology conditions and a set of biome-specific parameters (Xiao et al. 2004). Therefore, SIF is used to monitor drought much more directly than GPP. It should be noted that the change in SIF occurs earlier than the change in GPP due to the direct relationship between SIF and the vegetation physiological state.

NDVI is computed directly using visible and near-infrared sunlight reflected by the plants to display the 'green' information of the plants. Compared with GPP, NDVI reflects the vegetation condition more directly. Figure 7 shows that the change in SIF is consistent with NDVI variation from 2010 to 2017. It can clearly be seen that the occurrence of the decrease in SIF happens earlier than that of NDVI. This reveals that SIF can reflect variations in the vegetation physiological condition earlier than the reflectance. 

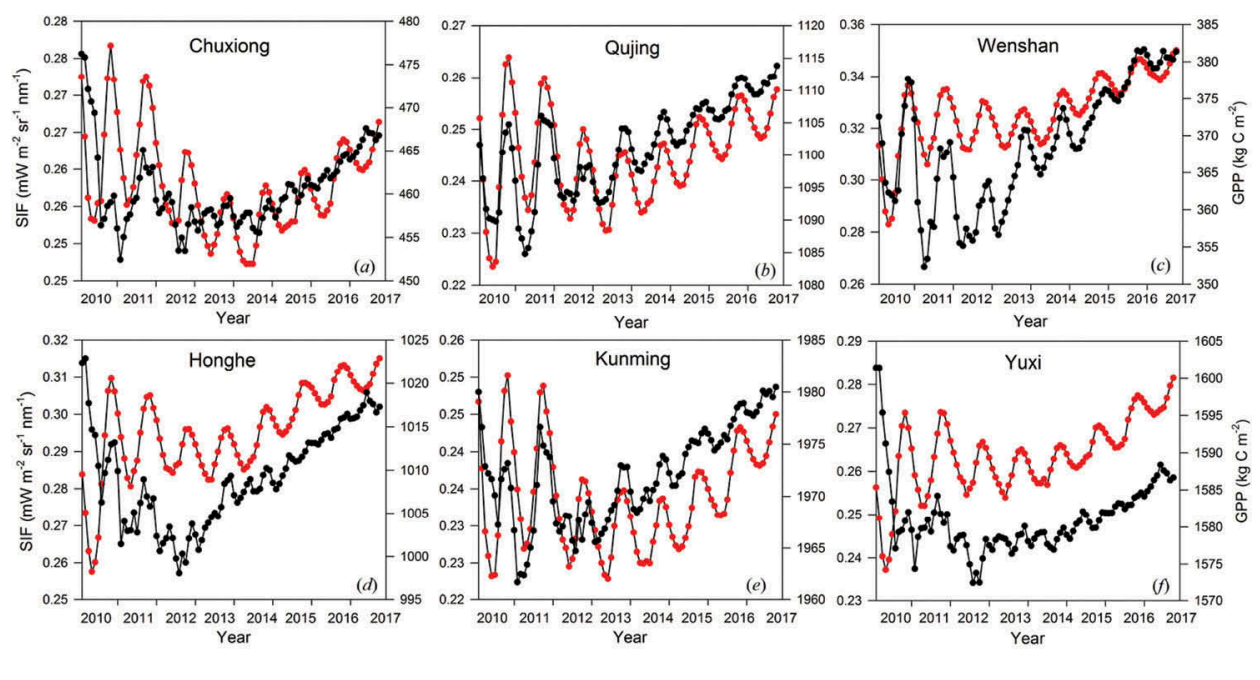

COLOUR FIGURE

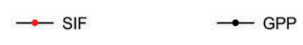

Figure 6. Annual variations in SIF and GPP from 2010 to 2017.
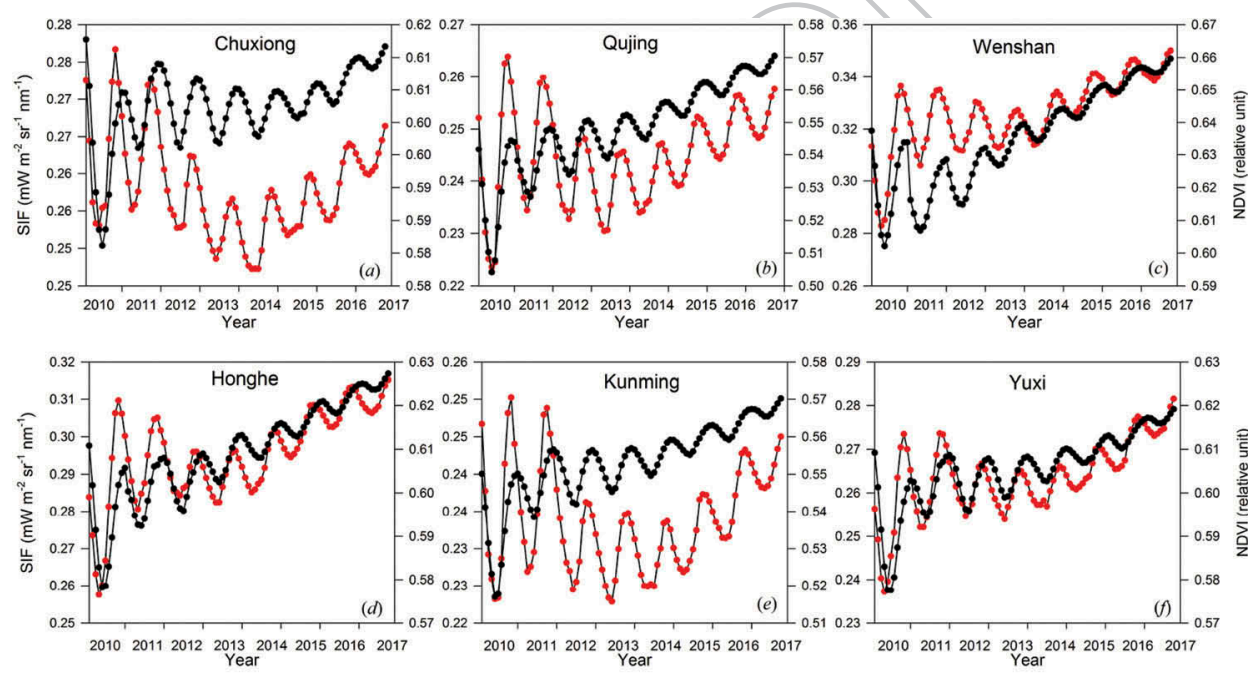

\section{Yuxi}
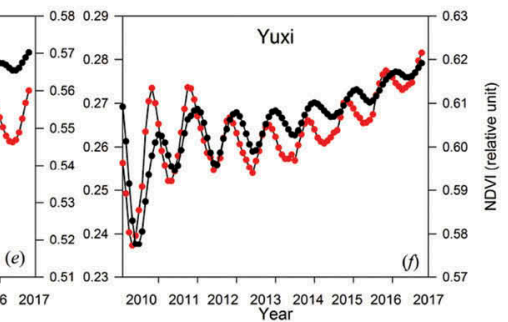

COLOUR FIGURE

$\rightarrow$ NDVI

Figure 7. Annual variations in SIF and NDVI from 2010 to 2017.

Photosynthesis, SIF and heat dissipation are three ways to consume absorbed energy by the plant. When the plant experiences water stress, fluorescence decreases, and the leaf temperature increases. Therefore, SIF and LST have opposing variation tendencies. Figure 8 shows that LST changes intensely from 2010 to 2013. LST is a good indicator when detecting water stress. It should be noted that the occurrence of the SIF minimum value happens earlier than the occurrence of the LST maximum value. It also illustrates that SIF has the advantage of reflecting changes in the physiological state of the plant. 

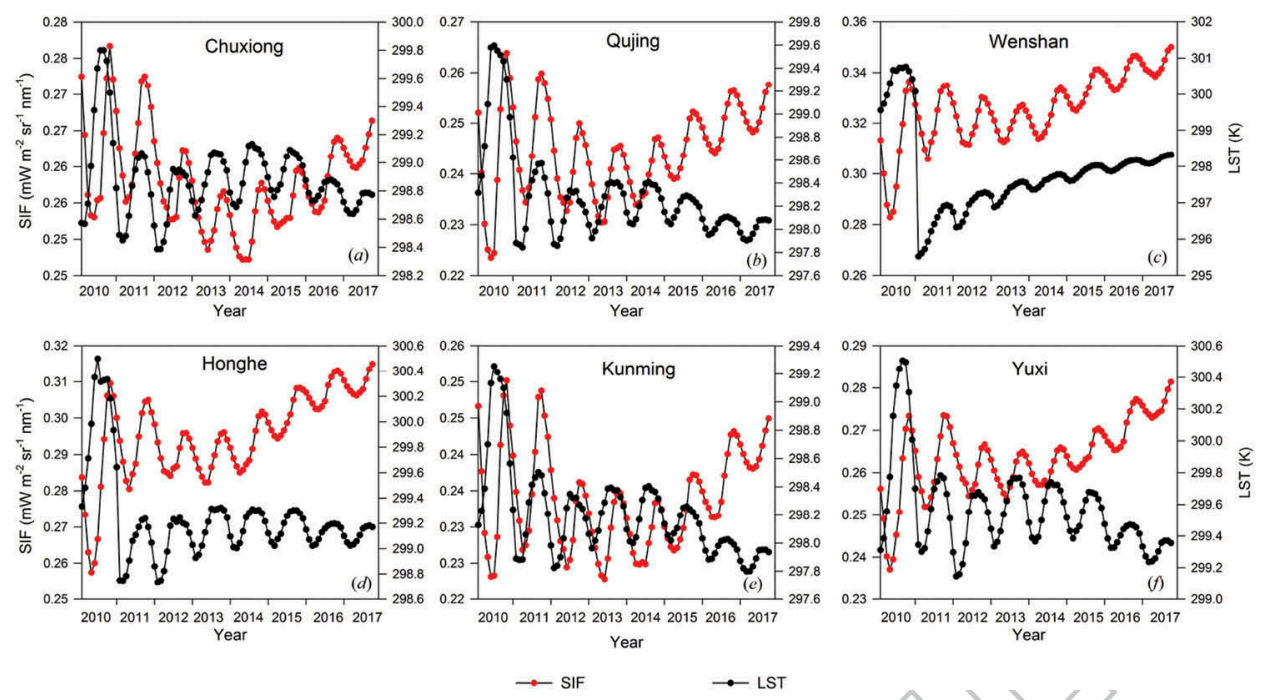

Figure 8. Annual variations in SIF and LST from 2010 to 2017.

\subsection{Relationship between SIF and soil moisture}

The GOME-2 monthly SIF and monthly soil moisture are used to analyse the relationship between SIF and soil moisture. Six areas, including Chuxiong, Qujing, Wenshan, Honghe, Kunming and Yuxi, in Yunnan, China, are combined to analyse the relationships among them from 2010 to 2016 . Soil moisture data are missing in 2017; therefore, the analysis is performed from 2010 to 2016 (Figure 10). The relationship between SIF and soil moisture is analysed, with $r=0.56$ in 2010 (Figure 9a), $r=0.71$ in 2011 (Figure 9b), $r=0.75$ in 2012 (Figure 9c), $r=0.74$ in 2013 (Figure 9d), $r=0.62$ in 2014 (Figure 9e), $r=0.52$ in 2015 (Figure 9f), and $r=0.47$ in 2016 (Figure 9g). The large correlation coefficients reveal that SIF has a close relationship with soil moisture. The correlation coefficient from 2010 to 2016 first increases, then decreases. Figure 10 shows that the soil moisture has increased gradually year by year since 2010. Figure 6 gives the annual variation in SIF and shows that SIF first decreases from 2010 to 2014, then gradually increases. By combining the variations in SIF and soil moisture from 2010 to 2014, it is revealed that SIF has a good relationship with soil water content under water stress conditions.

\section{Conclusions}

This paper showed the different responses of GOME-SIF, GPP, NDVI and LST in six areas of China to external environmental conditions, and illustrated the different performance of these parameters under the different water conditions. Yunnan Province suffered from a serious drought in 2010, and plants were under water stress. From 2010 to 2016, soil moisture varied gradually, and SIF, GPP, NDVI and LST has different responses correspondently. Six areas in Yunnan Province of China, including Chuxiong, Qujing, Honghe, Kunming, Wenshan and Yuxi, were selected as the research areas. SCOPE model 

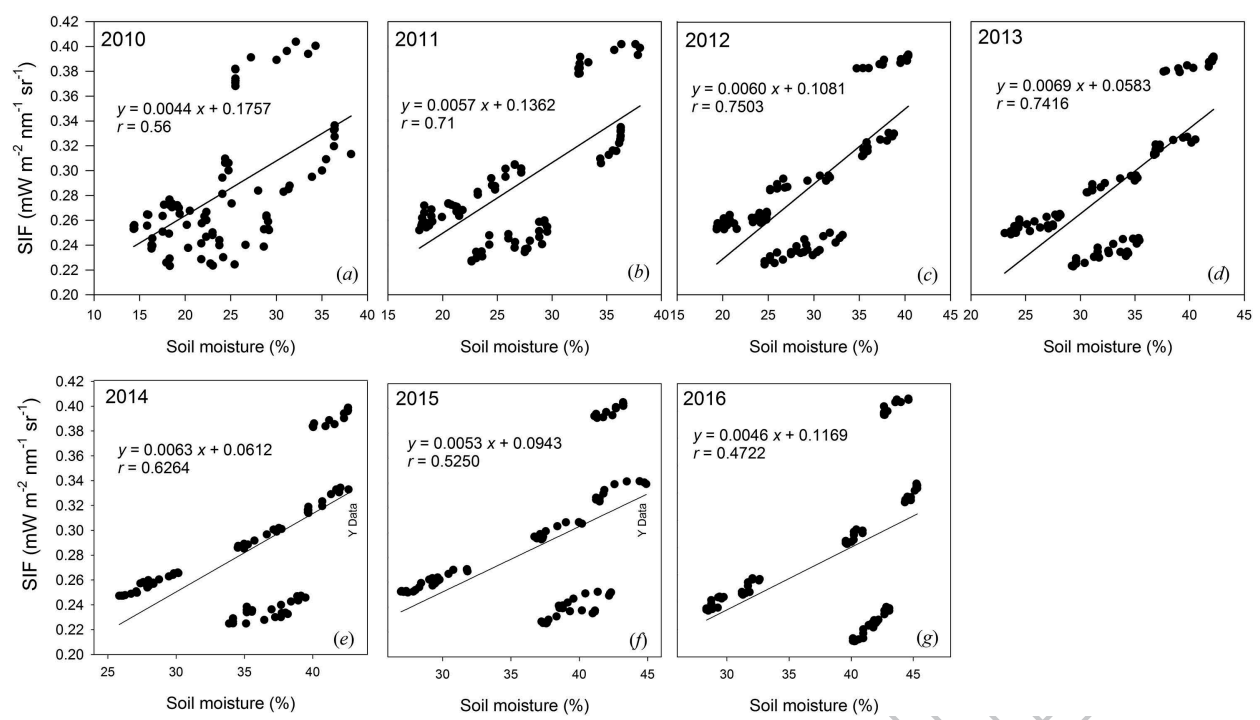

Figure 9. Relationship between SIF and soil moisture.

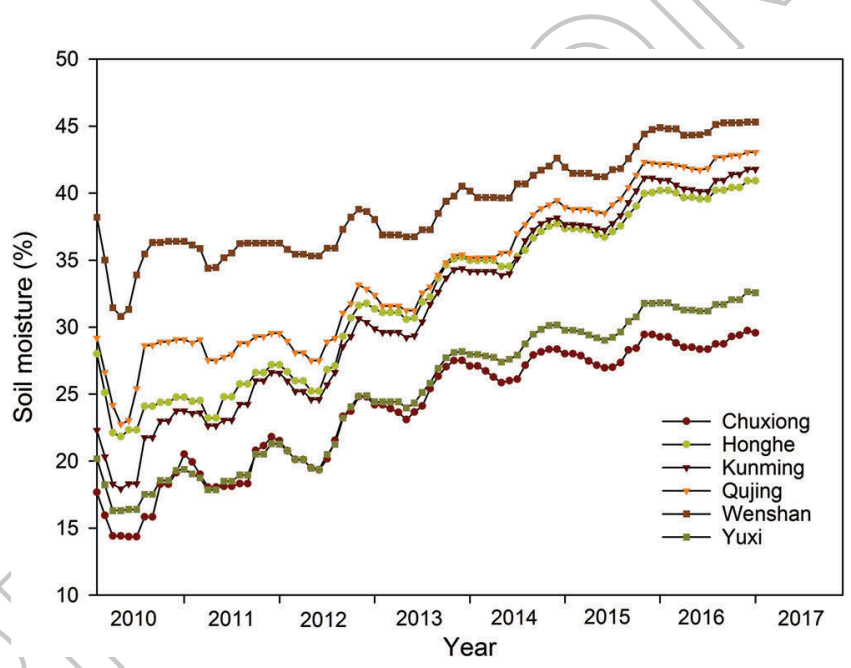

Figure 10. Soil moisture from 2010 to 2016.

was used to simulate canopy chlorophyll fluorescence and temperature. Through model simulation and satellite data analysis, it was easy to be accept that SIF is a good indicator for detecting vegetation physiological state changes.

The SCOPE model can regulate the stress factor to simulate variations in SIF and temperature at different stress levels. The stress factor acts on the $V_{\text {cmax }}$ then affects photosynthesis. The results show that SIF decreases, and temperature increases when stress deepens. This describes the daily response of SIF and temperature to stress from the view of model simulation and provides the theoretical support for drought detection in the Yunnan Province of China. 
The annual variations in SIF, GPP, NDVI, LST, precipitation and soil moisture are analysed in six areas. Due to the serious drought in 2010, the above parameters have different performances than those in other years. Precipitation and soil moisture from 2010 to 2014 increases gradually then decreases slightly. SIF begins with a decrease from 2010 to 2014, and is followed by an increase. By combining this with the variation in soil moisture, SIF first decreases then increases, which reveals that plants recover to a healthy condition after 2014. Despite the increase in precipitation and soil moisture, the plants are still under water stress conditions. Analysis of NDVI, GPP and LST have similar results, but these three parameters have less sensitivity to soil moisture change than SIF.

Long time-series analyses in 2010-2017 of SIF vs. GPP, SIF vs. NDVI and SIF vs. LST in the six areas are carried out. Except for GPP, the variations in NDVI and LST are consistent with those of SIF. SIF has a subtler change compared with the NDVI and LST. The most important observation is that SIF has an early response to water stress compared with the other parameters. When vegetation has the symptoms of water stress, SIF reflects the change earlier than NDVI or GPP. A correlation analysis between SIF and soil moisture is performed, and the results show a high correlation between SIF and soil moisture. This illustrates that SIF, which has a close relationship with photosynthesis, has the potential to detect water stress.

This paper analyses the variations in SIF, GPP, NDVI and LST from 2010 to 2017 in Yunnan Province of China and discusses the correction between SIF and soil moisture. The results show that SIF is a potential and effective indicator when detecting vegetation water stress. After analysing long time-series of satellite data, this work provides the support for monitoring drought using SIF. In the future, more relative meteorological data and drought indices should be considered to fully describe the relationship between SIF and vegetation stress.

\section{Acknowledgments}

The authors contributed equally to this work. Hongyuan Huo, Zhao-Liang Li, Shihao Tang and Zhigang Liu supervised this paper. Hongyuan Huo downloaded and processed the satellite data, and Shihao Tang revised this paper. Zhuoya Ni processed the satellite data and wrote the paper.

\section{Disclosure statement}

No potential conflict of interest was reported by the authors. [OFSLRSS201719];

\section{Funding}

This work was supported by the National Natural Science Foundation of China [41701421] and the Open Fund of the State Key Laboratory of Remote Sensing Science [Grant No. OFSLRSS201719]; Open Fund of State Key Laboratory of Remote Sensing Science 


\section{References}

Bellvert, J., J. Marsal, J. Girona, and P. J. Zarco-Tejada. 2015. "Seasonal Evolution of Crop Water Stress Index in Grapevine Varieties Determined with High-Resolution Remote Sensing Thermal Imagery." Irrigation Science 33 (2): 81-93. doi:10.1007/s00271-014-0456-y.

Bürling, K., Z. G. Cerovic, G. Cornic, J. M. Ducruet, G. Noga, and M. Hunsche. 2013. "FluorescenceBased Sensing of Drought-Induced Stress in the Vegetative Phase of Four Contrasting Wheat Genotypes." Environmental and Experimental Botany 89: 51-59. doi:10.1016/j. envexpbot.2013.01.003.

Campbell, P. E., E. M. Middleton, J. E. McMurtrey, and E. W. Chappelle. 2007. "Assessment of Vegetation Stress Using Reflectance or Fluorescence Measurements." Journal of Environmental Quality 36 (3): 832-845. doi:10.2134/jeq2005.0396.

Cheng, Y. B., E. M. Middleton, Q. Zhang, K. F. Huemmrich, P. K. E. Campbell, B. D. Cook, W. P. Kustas, and C. S. Daughtry. 2013. "Integrating Solar Induced Fluorescence and the Photochemical Reflectance Index for Estimating Gross Primary Production in a Cornfield." Remote Sensing 5 (12): 6857-6879. doi:10.3390/rs5126857.

Damm, A., L. Guanter, V. C. E. Laurent, M. E. Schaepman, A. Schickling, and U. Rascher. 2014. "FLDbased Retrieval of Sun-Induced Chlorophyll Fluorescence from Medium Spectral Resolution Airborne Spectroscopy Data." Remote Sensing of Environment 147: 256-266. doi:10.1016/j. rse.2014.03.009.

Damm, A., L. Guanter, E. Paul-Limoges, C. Van Der Tol, A. Hueni, N. Buchmann, W. Eugster, C. Ammann, and M. E. Schaepman. 2015. "Far-Red Sun-Induced Chlorophyll Fluorescence Shows Ecosystem-Specific Relationships to Gross Primary Production: An Assessment Based on Observational and Modeling Approaches." Remote Sensing of Environment 166: 91-105. doi:10.1016/j.rse.2015.06.004.

Dobrowski, S. Z., J. C. Pushnik, P. J. Zarco-Tejada, and S. L. Ustin. 2005. "Simple Reflectance Indices Track Heat and Water Stress-Induced Changes in Steady-State Chlorophyll Fluorescence at the Canopy Scale." Remote Sensing of Environment 97 (3): 403-414. doi:10.1016/j.rse.2005.05.006.

Flexas, J., J. M. Briantais, Z. Cerovic, H. Medrano, and I. Moya. 2000. "Steady-State and Maximum Chlorophyll Fluorescence Responses to Water Stress in Grapevine Leaves: A New Remote Sensing System." Remote Sensing of Environment 73 (3): 283-297. doi:10.1016/S0034-4257(00) 00104-8.

Flexas, J., J. M. Escalona, S. Evain, J. Gulías, 1. Moya, C. B. Osmond, and H. Medrano. 2002. "SteadyState Chlorophyll Fluorescence (Fs) Measurements as a Tool to Follow Variations of Net $\mathrm{CO}_{2}$ Assimilation and Stomatal Conductance during Water-Stress in C3 Plants." Physiologia Plantarum 114 (2): 231-240.

Frankenberg, C., J. B. Fisher, J. Worden, G. Badgley, S. S. Saatchi, J. E. Lee, G. C. Toon, A. Butz, M. Jung, and A. Kuze. $2011 \mathrm{~b}$. "New Global Observations of the Terrestrial Carbon Cycle from GOSAT: Patterns of Plant Fluorescence with Gross Primary Productivity." Geophysical Research Letters 38 (17). doi:10.1029/2011GL048738.

Fuchs, M., and C. B. Tanner. 1966. "Infrared Thermometry of Vegetation." Agronomy Journal 58 (6): 597-601. doi:10.2134/agronj1966.00021962005800060014x.

Gao, B. C. 1996. "NDWI—A Normalized Difference Water Index for Remote Sensing of Vegetation Liquid Water from Space." Remote Sensing of Environment 58 (3): 257-266. doi:10.1016/S00344257(96)00067-3.

Guan, K., J. A. Berry, Y. Zhang, J. Joiner, L. Guanter, G. Badgley, and D. B. Lobell. 2016. "Improving the Monitoring of Crop Productivity Using Spaceborne Solar-Induced Fluorescence." Glob Change Biol 22: 716-726. doi:10.1111/gcb.13136.

Guanter, L., C. Frankenberg, A. Dudhia, P. E. Lewis, J. Góez-Dans, A. Kuze, H. Suto, and R. G. Grainger. 2012. "Retrieval and Global Assessment of Terrestrial Chlorophyll Fluorescence from GOSAT Space Measurements." Remote Sensing of Environment 121: 236-251. doi:10.1016/j. rse.2012.02.006. 
Guanter, L., Y. Zhang, M. Jung, J. Joiner, M. Voigt, J. A. Berry, and C. Frankenberg. 2014. "Global and Time-Resolved Monitoring of Crop Photosynthesis with Chlorophyll Fluorescence." Proceedings of the National Academy of Sciences 111 (14): E1327-E1333. doi:10.1073/pnas.1320008111.

Hunt, E. R., and B. N. Rock. 1989. "Detection of Changes in Leaf Water Content Using Near-And Middle-Infrared Reflectances." Remote Sensing of Environment 30 (1): 43-54. doi:10.1016/00344257(89)90046-1.

IPCC. 2001. Climate Change 2001: Impacts, Adapation and Vulnerability of Climate Change, Working Group II Report. London,England: Cambrige University Press.

Jackson, R. D., S. B. Idso, R. J. Reginato, and P. J. Pinter. 1981. “Canopy Temperature as a Crop Water Stress Indicator." Water Resources Research 17 (4): 1133-1138. doi:10.1029/WR017i004p01133.

Joiner, J., Y. Yoshida, A. P. Vasilkov, and E. M. Middleton. 2011. "First Observations of Global and Seasonal Terrestrial Chlorophyll Fluorescence from Space." Biogeosciences 8 (3): 637-651. doi:10.5194/bg-8-637-2011.

Joiner, J., Y. Yoshida, A. P. Vasilkov, E. M. Middleton, P. K. E. Campbell, and A. Kuze. 2012. "Filling-In of Near-Infrared Solar Lines by Terrestrial Fluorescence and Other Geophysical Effects: Simulations and Space-Based Observations from SCIAMACHY and GOSAT." Atmospheric Measurement Techniques 5 (4): 809-929. doi:10.5194/amt-5-809-2012.

Liu, Y. Y., W. A. Dorigo, et al. 2012. "Trend-Preserving Blending of Passive and Active Microwave Soil Moisture Retrievals". Remote Sensing of Environment 123: 280-297. doi:10.1016/j. rse.2012.03.014.

Liu, Y. Y., R. M. Parinussa, W. A. Dorigo, R. A. M. De Jeu, W. Wagner, A. I. J. M. Van Dijk, M. F. McCabe, and J. P. Evans. 2011. "Developing an Improved Soil Moisture Dataset by Blending Passive and Active Microwave Satellite-Based Retrievals." Hydrology and Earth System Sciences 15: 425-436. doi:10.5194/hess-15-425-2011.

Ma, S., Q. Wu, J. Wang, and S. Zhang. 2017. "Temporal Evolution of Regional Drought Detected from GRACE TWSA and CCI SM in Yunnan Province, China." Remote Sensing 9: 1124. doi:10.3390/ rs9111124.

Marcassa, J. C., J. Ferreira, S. Zucoloto, O. D. C. Silva Jr, L. G. Marcassa, and V. S. Bagnato. 2006. "Detection of Hepatocarcinoma in Rats by Integration of the Fluorescence Spectrum: Experimental Model." Laser Physics 16 (5): 827-832. doi:10.1134/S1054660X06050136.

Meroni, M., M. Rossini, L. Guanter, L. Alonso, U. Rascher, R. Colombo, and J. Moreno. 2009. "Remote Sensing of Solar-Induced Chlorophyll Fluorescence: Review of Methods and Applications." Remote Sensing of Environment 113 (10): 2037-2051. doi:10.1016/j.rse.2009.05.003.

Miller, J. R., M. Berger, Y. Goulas, S. Jacquemoud, J. Louis, G. Monhammed, N. Moise, et al. 2005. "Development of a Vegetation Fluorescence Canopy Model, ESTEC Contract No.16365/02/NL/FF, Final Report".

Monteith, J. L. 1972. "'Solar Radiation and Production in Tropical Ecosystems."." J. Appl. Ecol. 9: 747-766. doi:10.2307/2401901.

Ni, Z., Z. Liu, H. Huo, Z.-L. Li, F. Nerry, Q. Wang, and X. Li. 2015a. "Early Water Stress Detection Using Leaf-Level Measurements of Chlorophyll Fluorescence and Temperature Data." Remote Sensing 7 (3): 3232-3249. doi:10.3390/rs70303232.

Ni, Z., Z. Liu, Z.-L. Li, F. Nerry, H. Huo, and X. Li. 2015b. "Estimation of Solar-Induced Fluorescence Using the Canopy Reflectance Index." International Journal of Remote Sensing 36 (19-20): 52395256. doi:10.1080/01431161.2015.1058987.

Ni, Z., Z. Liu, Z.-L. Li, F. Nerry, H. Huo, R. Sun, P. Yang, and W. Zhang. 2016. "Investigation of Atmospheric Effects on Retrieval of Sun-Induced Fluorescence Using Hyperspectral Imagery." Sensors 16: 480. doi:10.3390/s16122100.

Paloscia, S., and P. Pampaloni. 1984. "Microwave Remote Sensing of Plant Water Stress." Remote Sensing of Environment 16 (3): 249-255. doi:10.1016/0034-4257(84)90068-3.

Perez-Priego, O., J. Guan, M. Rossini, F. Fava, T. Wutzler, G. Moreno, N. Carvalhais, A. Carrara, O. Kolle, and T. Julitta. 2015. "Sun-Induced Chlorophyll Fluorescence and PRI Improve Remote Sensing GPP Estimates under Varying Nutrient Availability in a Typical Mediterranean Savanna Ecosystem." Biogeosciences Discussions 12 (14). doi:10.5194/bgd-12-11891-2015. 
Pérez-Priego, O., P. J. Zarco-Tejada, J. R. Miller, G. Sepulcre-Cantó, and E. Fereres. 2005. “Detection of Water Stress in Orchard Trees with a High-Resolution Spectrometer through Chlorophyll Fluorescence In-Filling of the $\mathrm{O}_{2}$-A Band." Geoscience and Remote Sensing, IEEE Transactions On 43 (12): 2860-2869. doi:10.1109/TGRS.2005.857906.

Peters, A. J., E. A. Walter-Shea, L. Ji, A. Vina, M. Hayes, and M. D. Svoboda. 2002. "Drought Monitoring with NDVI-based Standardized Vegetation Index." Photogrammetric Engineering and Remote Sensing 68 (1): 71-75.

Product Specification Document (PSD) D1.2.1 Version3.3. 2017. Earth observation Data Centre for Water Resources Monitoring (EODC) GmbH, 20 November.

Qiu, J. 2010. "China Drought Highlights Future Climate Threats." Nature 465: 142-143. doi:10.1038/ 465142a.

Rahbarian, R., Khavari-Nejad, R., Ganjeali, A., et al. 2011. "Drought Stress Effects on Photosynthesis, Chlorophyll Fluorescence and Water Relations in Tolerant and Susceptible Chickpea (Cicer Arietinum L.) Genotypes." Acta Biologica Cracoviensia Series Botanica 53 (1): 47-56.

Rosema, A., J. F. H. Snel, H. Zahn, W. F. Buurmeijer, and L. W. A. Van Hove. 1998. "The Relation between Laser-Induced Chlorophyll Fluorescence and Photosynthesis." Remote Sensing of Environment 65 (2): 143-154. doi:10.1016/S0034-4257(98)00020-0.

Sandholt, I., K. Rasmussen, and J. Andersen. 2002. "A Simple Interpretation of the Surface Temperature/Vegetation Index Space for Assessment of Surface Moisture Status." Remote Sensing of Environment 79 (2): 213-224. doi:10.1016/S0034-4257(01)00274-7.

Smorenburg, K., C. -. L. Gregory Bazalgette, B. Michael, B. Claus, J. C. Andrew, D. B. Umberto, and L. Gabriele. 2002. "Remote Sensing of Solar-Induced Fluorescence of Vegetation." International Symposium on Remote Sensing. doi:10.1044/1059-0889(2002/er01)

Thum, T., S. Zaehle, P. Köhler, T. Aalto, M. Aurela, L. Guanter, P. Kolari, et al. 2017. "Modelling SunInduced Fluorescence and Photosynthesis with a Land Surface Model at Local and Regional Scales in Northern Europe." Biogeosciences 14 (7): 1969-1987. doi:10.5194/bg-14-1969-2017.

Vereecken, H., L. Weihermüller, F. Jonard, and C. Montzka. 2012. "Characterization of Crop Canopies and Water Stress Related Phenomena Using Microwave Remote Sensing Methods: A Review." Vadose Zone Journal 11 (2). doi:10.2136/vzj2011.0138ra.

Wagner, W., W. Dorigo, R. De Jeu, D. Fernandez, J. Benveniste, E. Haas, and M. Ertl. 2012. "Fusion of Active and Passive Microwave Observations to Create an Essential Climate Variable Data Record on Soil Moisture." ISPRS Annals of the Photogrammetry, Remote Sensing and Spatial Information Sciences (ISPRS Annals), Volume I-7, XXII ISPRS Congress, Melbourne, Australia, 25 August-1 September 2012, 315-321.

Walker, J. P. 1999. Estimating Soil Moisture Profile Dynamics from Near-Surface Soil Moisture Measurements and Standard Meteorological Data. University of Newcastle.

Wang, H., A. Chen, Q. Wang, and B. He. 2015. "Drought Dynamics and Impacts on Vegetation in China from 1982 to 2011." Ecological Engineering 75 (303-307): 0925-8574. ISSN. doi:10.1016/j. ecoleng.2014,11.063.

Wang, L., and/J. J. Qu. 2009a. "Satellite Remote Sensing Applications for Surface Soil Moisture Monitoring: A Review." Frontiers of Earth Science in China 3 (2): 237-247. doi:10.1007/s11707009-0023-7.

Wang, L., and J. J. Qu. 2009b. "Satellite Remote Sensing Applications for Surface Soil Moisture Monitoring: A Review." Frontiers of Earth Science in China 3 (2): 237-247. doi:10.1007/s11707009-0023-7.

Wu, C., Z. Niu, and S. Gao. 2010. "Gross Primary Production Estimation from MODIS Data with Vegetation Index and Photosynthetically Active Radiation in Maize." J. Geophys. Res. 115: D12127. doi:10.1029/2009JD013023.

Xiao, X., D. Hollinger, J. Aber, M. Goltz, E. A. Davidson, Q. Zhang, and B. Moore. 2004. "SatelliteBased Modeling of Gross Primary Production in an Evergreen Needleleaf Forest." Remote Sensing of Environment 89 (4): 519-534. doi:10.1016/j.rse.2003.11.008.

Xu, L., A. Samanta, M. H. Costa, S. Ganguly, R. R. Nemani, and R. B. Myneni. 2011. “Widespread Decline in Greenness of Amazonian Vegetation Due to the 2010 Drought." Geophys. Res. Lett 38. doi:10.1029/2011GL046824. 
Yang, X., J. Tang, F. M. John, J. Lee, M. Rossini, J. Joiner, J. W. Munger, A. Kornfeld, and A. D. Richardson. 2015. "Solar-Induced Chlorophyll Fluorescence that Correlates with Canopy Photosynthesis on Diurnal and Seasonal Scales in a Temperate Deciduous Forest." Geophysical Research Letters 42 (8): 2977-2987. doi:10.1002/2015GL063201.

Zarco-Tejada, P. J. 2005. "Development of a Vegetation Fluorescence Canopy Model." In ESA Scientific and Technical Publications Branch, ESTEC. Paris.

Zarco-Tejada, P. J., J. A. J. Berni, L. Suárez, G. Sepulcre-Cantó, F. Morales, and J. R. Miller. 2009. "Imaging Chlorophyll Fluorescence with an Airborne Narrow-Band Multispectral Camera for Vegetation Stress Detection." Remote Sensing of Environment 113 (6): 1262-1275. doi:10.1016/j. rse.2009.02.016.

Zarco-Tejada, P. J., A. Catalina, M. R. González, and P. Martín. 2013a. "Relationships between Net Photosynthesis and Steady-State Chlorophyll Fluorescence Retrieved from Airborne Hyperspectral Imagery." Remote Sensing of Environment 136: 247-258. doi:10.1016/j. rse.2013.05.011.

Zarco-Tejada, P. J., V. González-Dugo, and J. A. J. Berni. 2012. "Fluorescence, Temperature and Narrow-Band Indices Acquired from a UAV Platform for Water Stress Detection Using a MicroHyperspectral Imager and a Thermal Camera." Remote Sensing of Environment 117: 322-337. doi:10.1016/j.rse.2011.10.007.

Zarco-Tejada, P. J., J. R. Miller, R. Pedros, W. Verhoef, and M. Berger. 2004a. "FluorMODgui: A Graphic User Interface for the Spectral Simulation of Leaf and Canopy Fluorescence Effects." In $2^{\text {nd }}$ International Workshop on Remote Sensing of Vegetation Fluorescence. Canada,North America: Montreal.

Zarco-Tejada, P. J., O. Pérez-Priego, G. Sepulcre-Cantó, J. R. Miller, and C. E. Fereres. 2004b. Chlorophyll Fluorescence Detection with a High-Spectral Resolution Spectrometer through InFilling of the $\mathrm{O}_{2}-\mathrm{A}$ Band as Function of Water Stress in Olive Trees.

Zhang, Y., L. Guanter, J. A. Berry, C. Van Der Tol, X. Yang, J. Tang, and F. Zhang. 2016. "Model-Based Analysis of the Relationship between Sun-Induced Chlorophyll Fluorescence and Gross Primary Production for Remote Sensing Applications." Remote Sensing of Environment 187 (Supplement C): 145-155. doi:10.1016/j.rse.2016.10.016.

Zhang, Y., G. Luis, J. A. Berry, J. Joiner, C. Tol, A. Huete, A. Gitelson, M. Voigt, and K. Philipp. 2014. "Estimation of Vegetation Photosynthetic Capacity from Space-Based Measurements of Chlorophyll Fluorescence for Terrestrial Biosphere Models." Global Change Biology 20 (12): 3727-3742. doi:10.1111/gcb.12664.

Zlatev, Z. S., and I. T. Yordanov. 2004. "Effects of Soil Drought on Photosynthesis and Chlorophyll Fluorescence in Bean Plants." Bulg. J. Plant Physiol 30 (3-4): 3-18. 